УДК $581.132+633.31$

DOI 10.36461/NP.2020.54.1.004

\title{
СРОКИ ПОСЕВА И ФОТОСИНТЕТИЧЕСКАЯ ДЕЯТЕЛЬНОСТЬ АГРОЦЕНОЗА ЛЮЦЕРНЫ ИЗМЕНЧИВОЙ ПЕРВОГО ГОДА ЖИЗНИ
}

В. А. Гущина, доктор с.-х. наук, профрессор; О. А. Тимошкин“, доктор с.-х. наук, доцент;

Г. В. Ильина, доктор биол. наук, профрессор; Г. Н. Володькина, аспирант

Федеральное государственное бюджетное образовательное учреждение высшего

образования «Пензенский государственный аграрный университет», Россия,

т. 8(8412) 62-83-67, e-mail: guschina.v.a@pgau.ru;

*ФГБНУ «Федеральный научный центр лубяных культур», р. п. Лунино,

Пензенская область, Россия, т. +7 (84161) 3-18-14, e-mail: oatimoshkin@mail.ru

В связи с широким ареалом возделывания люцерны и повышения эффективности её использования в современном сельском хозяйстве необходимо внедрять сорта нового поколения, обладающие широкой амплитудой устойчивости к абиотическим стрессовым фракторам. Разработка приемов возделывания люцерны изменчивой сорта Дарья предусматривает использование резервов фотосинтетической деятельности для повышения её продуктивности. Поэтому целью исследований является определение оптимального срока посева люцерны изменчивой, при котором формируются высокие урожаи за счет лучшего использования фотосинтетической функции растений. Эксперимент проводили на опытном поле Пензенского ИСХ - филиала ФГБНУ «Федеральный центр лубяных культур» в 2017-2019 гг. на черноземе выщелоченном, где изучали четыре срока посева: первый - ранневесенний (1-10 мая), совпадающий с физической спелостью почвы; второй - поздневесенний (20-30 мая) и два срока посева, проведенные в летний период: 1-10 июня, последующий с интервалом в 30 дней к предыдущему. Годы исследований характеризовались как сухие и засушливые. Наиболее оптимальные условия для развития ассимиляционной поверхности растений первого года жизни складывались на ранневесенних посевах, где площадь листьев была наибольшей 30,5 тыс. м $^{2}$ га. По мере сокращения вегетационного периода наблюдается снижение индекса листовой поверхности в 1,5 раза. Наиболее интенсивное формирование ассимиляционной поверхности происходило в 2017 году и ее площадь составила $35,8 \ldots 19,7$ тыс. м²/га, максимума она достигала при раннем посеве. В этом же году отмечена наибольшая величина фотосинтетического потенциала 1001 ...2638 тыс. м² сутки/га. В среднем за три года максимальный $-2129,3$ тыс. м².сутки/га он формировался у растений при посеве ранней весной, а чистая продуктивность фотосинтеза находилась в диапазоне от 0,87 до 0,93 г/м ${ }^{2}$ сутки. Наибольший показатель установлен при ранних посевах, что способствовало накоплению 2,0 т/га сухого вещества.

Ключевые слова: люцерна изменчивая, сроки сева, чистая продуктивность фотосинтеза, фоотосинтетический потенциал, продуктивность.

\section{Введение}

Одним из главных принципов организации кормопроизводства является создание устойчивой кормовой базы, позволяющей повысить продуктивность животноводства. Проблема обеспечения животных кормами в первой половине пастбищного периода в Среднем Поволжье решена за счет многолетних бобовых и злаковых трав и их смесей [2]. Для увеличения производства зеленой массы во второй половине лета необходимо расширить набор кормовых культур с высокой и стабильной урожайностью, отавностью, хорошей поедаемостью, технологичностью заготовки и хранения, минимальными затратами на возделывание и хранение [6]. Ведущее место среди них занимает люцерна. В связи с широким ареалом ее возделывания и повышения эфффективности использования, в современном сельском хозяйстве необходимо внедрять сорта нового поколения, обладающие широкой амплитудой устойчивости к абиотическим стрессовым фракторам.

Одной из таких культур является люцерна изменчивая сорта Дарья, выведенного сотрудниками ФГБНУ «Пензенский HИИСХ» и внесенного в государственный реестр селекционных достижений, допущенных к использованию.

Повышение продуктивности растений обеспечивается балансом двух основных процессов их жизнедеятельности - фотосинтеза и роста [7, 19]. Разработка приемов возделывания люцерны изменчивой 
предусматривает использование резервов фотосинтетической деятельности для повышения ее продуктивности. Поэтому целью исследований является определение оптимального срока посева люцерны изменчивой, при котором формируются высокие урожаи за счет лучшего использования фотосинтетической функции растений и результатов ее активности.

\section{Методы и материалы}

Экспериментальную работу проводили на опытном поле Пензенского ИСХ - филиала ФГБНУ «Федеральный центр лубяных культур» в 2017-2019 гг.

Почва опытного участка чернозём выщелоченный среднемощный тяжёлосуглинистый. Содержание гумуса в пахотном горизонте - 6,2-6,5 \%, реакция среды близкая к нейтральной ( $\left.\mathrm{pH}_{\text {сол }} 5,6-5,8\right)$, содержание легкогидролизуемого азота высокое 85-97 мг/кг, повышенное содержание подвижного фосфора - 165-176 и обменного калия - 133-152 мг на 1 кг почвы. Предшественник - вико-овсяная смесь на сено.

Обработка почвы состояла из зяблевой вспашки, ранневесеннего боронования, предпосевной культивации и прикатывания. Посев проводили сеялкой $\mathrm{CH}-16$ рядовым способом с нормой высева 6 млн. всхожих семян на 1 га. Для снижения твердокаменности семян и увеличения их всхожести посевной материал люцерны скарифицировали. Непосредственно перед посевом проведена инокуляция препаратом Гумариз (ризоторфин, обогащенный микроэлементами). После посева почву прикатали кольчато-шпоровыми катками ЗККШ-6.

Люцерна изменчивая сорта Дарья по продуктивности превосходит самые распространенные сорта люцерны. За счет корнеотпрысковой корневой системы она отличается продуктивным долголетием и устойчивостью к стрессовым условиям погоды, которые проявляются в виде засухи и сильных весенних ветров. В связи с эти схема опыта включала четыре срока посева: первый - ранневесенний (1-10 мая), который совпадает с физической спелостью почвы; второй - поздневесенний (2030 мая) и два срока посева, проведенные в летний период: 1-10 июня, последующий с интервалом в 30 дней к предыдущему (1-10

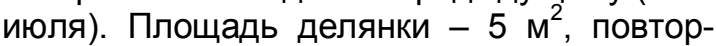
ность опыта четырехкратная, размещение делянок - систематическое.

Опыты проводились в соответствии с методическими указаниями Б. А. Доспехова (1985) [4], ВНИИ кормов им. В. Р. Вильямса (1983) [8]. Показатели фотосинтетической деятельности растений в посевах опреде- ляли по методике А. А. Ничипоровича (1961) [9], чистая продуктивность фоотосинтеза по фрормуле, предложенной L. Briggs, F. Kidd, C. West. Основные показатели продуктивности изучали по общепринятым методикам.

В годы проведения исследований сложились достаточно неблагоприятные погодные условия. Отсутствие осадков в первой декаде мая 2017 года и низкие среднесуточные температуры $\left(12,4{ }^{\circ} \mathrm{C}\right)$ с заморозками на почве в двух следующих декадах привели к тому, что на первом сроке посева, проведенном 2 мая, всходы появились поздно - 17 числа, на втором (посев 26 мая) - полные всходы отмечены 9 июня, то есть, так же, как и на первом - на пятнадцатые сутки, поскольку в третьей декаде выпало три нормы осадков. Дефицит осадков и низкие среднесуточные температуры июня при гидротермическом коэффрициенте (ГТК) - 0,3 задержали появление всходов на посевах, проведенных 7 июня. С высокой изреженностью они появились на четырнадцатые сутки. Посевы последнего срока, проведенные 2 июля, взошли на четырнадцатый день, чему способствовали осадки, выпавшие в конце первой декады месяца. Засушливый август (ГТК - 0,1) не сильно повлиял на сохранность растений люцерны всех сроков сева, так как к этому времени интенсивно развилась корневая система. Эта биологическая особенность культуры повышает ее устойчивость к заcyxe.

Вегетационный период 2018 г. характеризовался как сухой, ГТК составил 0,4. В этом году заложена вторая плантация по изучаемой схеме. Используя осенне-зимние запасы влаги на ранневесеннем посеве люцерны, достаточно дружные всходы получены на четырнадцатый день. Отсутствие осадков на момент последующих трех сроков посева привело к тому, что только после их выпадения в первых двух декадах июля, всходы появились почти одновременно. Причем количество осадков было ниже нормы на $36 \%$. За вегетацию их выпало в 2,3 раза меньше климатической нормы при температуре воздуха выше среднемноголетней на $2,7^{\circ} \mathrm{C}$.

Аналогичные условия, как и в 2018 году, сложились для вновь посеянной люцерны в 2019 году. Сумма осадков с мая по вторую декаду июня была в два раза меньше нормы. Поэтому все посевы люцерны взошли в июле, кроме проведенных ранней весной. Гидротермический коэффициент вегетационного периода третьего года исследований составил 0,67. При среднесуточной температуре воздуха $16,1^{\circ} \mathrm{C}$ 
осадков выпало 74,0 \% от среднемноголетних. Повышенными температурами характеризовался май $\left(16,2{ }^{\circ} \mathrm{C}\right.$ при норме $\left.13,6{ }^{\circ} \mathrm{C}\right)$, причем осадков было почти в полтора раза меньше климатической нормы. Особенно жарким и сухим было начало июня. Среднесуточная температура воздуха превышала среднемноголетнюю на 1,8 ${ }^{\circ} \mathrm{C}$. И только в третьей декаде месяца выпала основная часть осадков - 32,6 мм, что составило $63 \%$ от месячной нормы. Наибольшее снижение температуры по сравнению с многолетней наблюдалось в июле. В это же время сумма выпавших осадков была ниже нормы на 21,2 мм (ГТК - 0,74). Прохладнее обычного было в августе (на $\left.1,{ }^{\circ} \mathrm{C}\right)$, при дефиците осадков 16,1 мм. Большая их часть, выпавших в первой декаде (28,6 мм), нивелировала последствия засухи во второй и третьей декадах августа. Пониженными температурами характеризовался сентябрь $\left(10,5{ }^{\circ} \mathrm{C}\right.$ против 11,7 $\left.{ }^{\circ} \mathrm{C}\right)$. Осадков выпало 96 \% от нормы, причем основная их доля приходилась на вторую половину месяца, что позволило растениям люцерны накопить пластические вещества для лучшей перезимовки.

Таким образом, в годы проведения исследований (2017-2019 гг.) наблюдались значительные колебания температур и условий увлажнения. Продолжительность вегетационного периода люцерны первого года жизни в зависимости от сроков посева составила 40-98 дней, сумма активных температур и осадков 1051,9-1772 ${ }^{\circ} \mathrm{C}$ и 55,6-102 мм соответственно. По гидротермическим условиям годы характеризовались как сухие (ГТК - 0,4) и засушливые
(ГТК - 0,8), при значительных различиях не только по месяцам, но и по декадам.

\section{Результаты}

Основой получения высоких и устойчивых урожаев сельскохозяйственных культур в условиях интенсивного земледелия является комплексная теория фотосинтетической продуктивности растений [11], которая должна давать представление о максимально возможной продуктивности сельскохозяйственных культур при соответствующей разработанной технологии, отвечающей биологическим требованиям сорта.

Являясь важнейшим процессом в жизни растений, фотосинтез определяет их обеспеченность питательными веществами, необходимыми для роста и развития, а в конечном итоге и получения качественного урожая, поскольку до 90-95\% сухой биомассы растений образуется в результате фотосинтеза и быстрого транспорта ассимиляторов. Поэтому в формировании урожая этому процессу принадлежит ведущая роль [9].

Одним из основных, но наиболее изменчивых показателей фотосинтетической деятельности посевов является величина листовой поверхности - главнейший аппарат взаимодействия растений со средой, при помощи которого улавливается энергия солнечной радиации, преобразующаяся в потенциальную энергию органического вещества в процессе фоотосинтеза [10]. Ученые отмечают, что размер и динамика развития листовой поверхности находится под воздействием многочисленных биологических и климатических фракторов, а так-

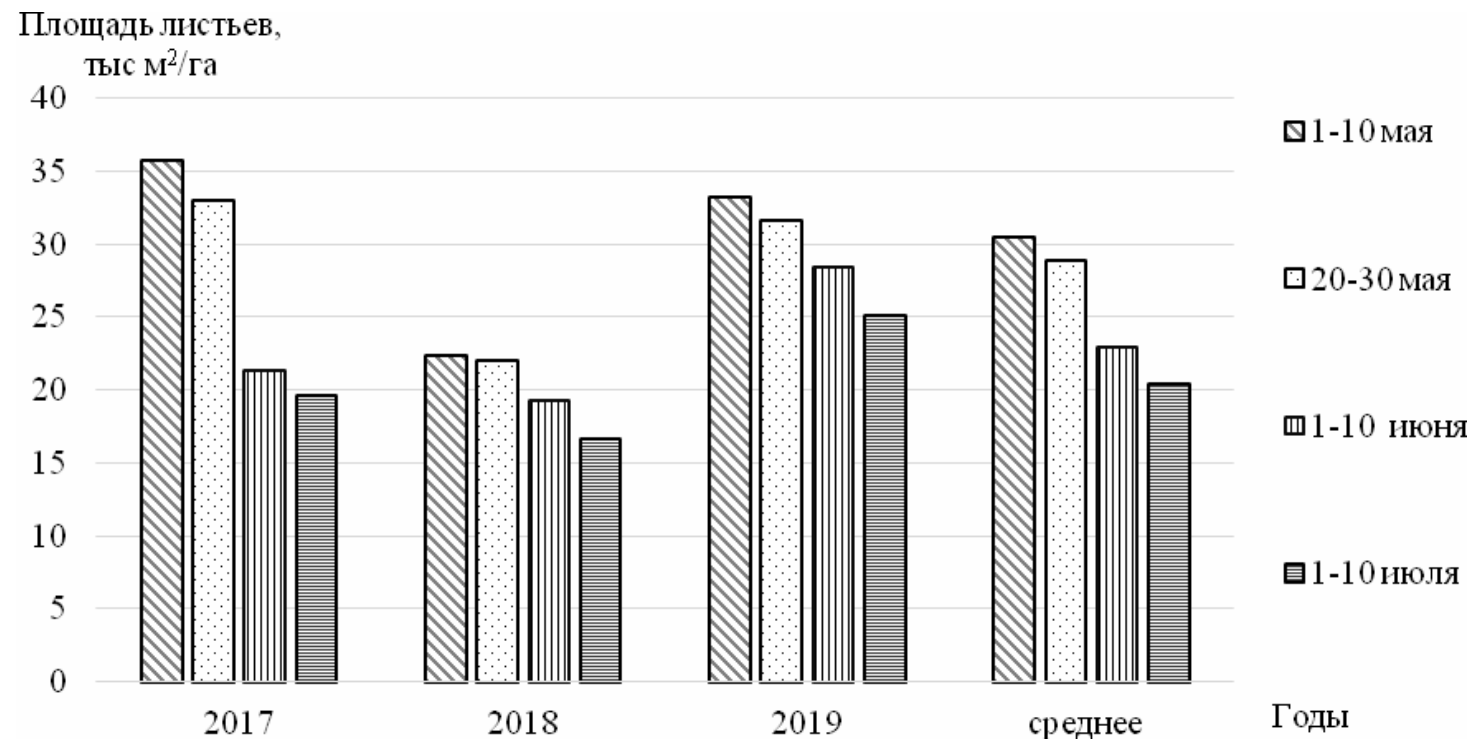

Puc. 1. Ассимиляционная поверхность люцерны изменчивой первого года жизни, mыс. $\mathrm{M}^{2} / 2 a$ 
же существенно зависит от приемов агротехники $[14,16,17,19]$, в том числе и от сроков посева [13].

Наиболее оптимальные условия для развития ассимиляционной поверхности люцерны изменчивой первого года жизни в среднем за три года складывались на ранневесенних посевах, где площадь листьев к концу сентября была наибольшей - 30,5 тыс. м $^{2} /$ га. По мере сокращения вегетационного периода, связанного с более поздними посевами, наблюдается снижение индекса листовой поверхности в 1,5 раза (рис. 1).

По годам исследований формирование листовой поверхности наиболее интенсивно происходило в 2017 году и ее площадь составила 35,8-19,7 тыс. м²/га. Максимальную площадь листьев растения достигали при раннем посеве (1-10 мая). На посевах в третьей декаде мая фотосинтезирующая поверхность уменьшилась на 2,8 тыс. м $^{2} /$ га. Летние посевы были менее развиты, причем лучшие условия складывались для растений июньского посева, где, несмотря на более развитые растения, густота травостоя была снижена, площадь ассимиляционной поверхности составила 21,4 тыс. $\mathrm{m}^{2} /$ га.

При засушливых условиях 2018 года, формирование ассимиляционной поверхности происходило слабее, и она была в 1,1-1,6 раза меньше, чем в предшествующем году. В третий год исследований, при ГТК - 0,67, площадь листьев находилась на уровне $25,0-33,2$ тыс. м $^{2} /$ га.
Более точным показателем, определяющим продуктивность процесса фротосинтеза, является фотосинтетический потенциал (ФП), учитывающий площадь листьев и время работы листовой поверхности $[1,4]$. Формирование фотосинтетического потенциала происходит в соответствии с нарастанием листьев [3].

В среднем за три года максимальный фотосинтетический потенциал в первый год жизни люцерны изменчивой формировался у растений при посеве ранней весной (1-10 мая) и к концу вегетационного периода составил 2129,3 тыс. м².сутки/га (рис. 2).

Следует отметить, что фотосинтетический потенциал, как и площадь листовой поверхности, зависит не только от сроков посева, но и от влагообеспеченности года. Благодаря лучшему развитию ассимиляционной поверхности наибольшая величина ФП 1001-2638 тыс. м² сутки/га отмечена в 2017 году. Оптимальная густота стеблестоя люцерны на первом сроке посева оказала положительное влияние на фотосинтетический потенциал. Растения второго срока сева (20-30 мая) уступают по развитию растениям ранневесеннего посева, следовательно, они меньше аккумулируют энергию солнца и их фотосинтетический потенциал ниже - 2256 тыс. м² сутки/га. На июньских посевах он снизился в 1,6 раза по отношению к предыдущему сроку.

Значительно ниже был фотосинтетический потенциал в 2018 году из-за слабого развития листовой поверхности. Минималь-

Тыс. $\mathrm{M}^{2}$

сутки/га

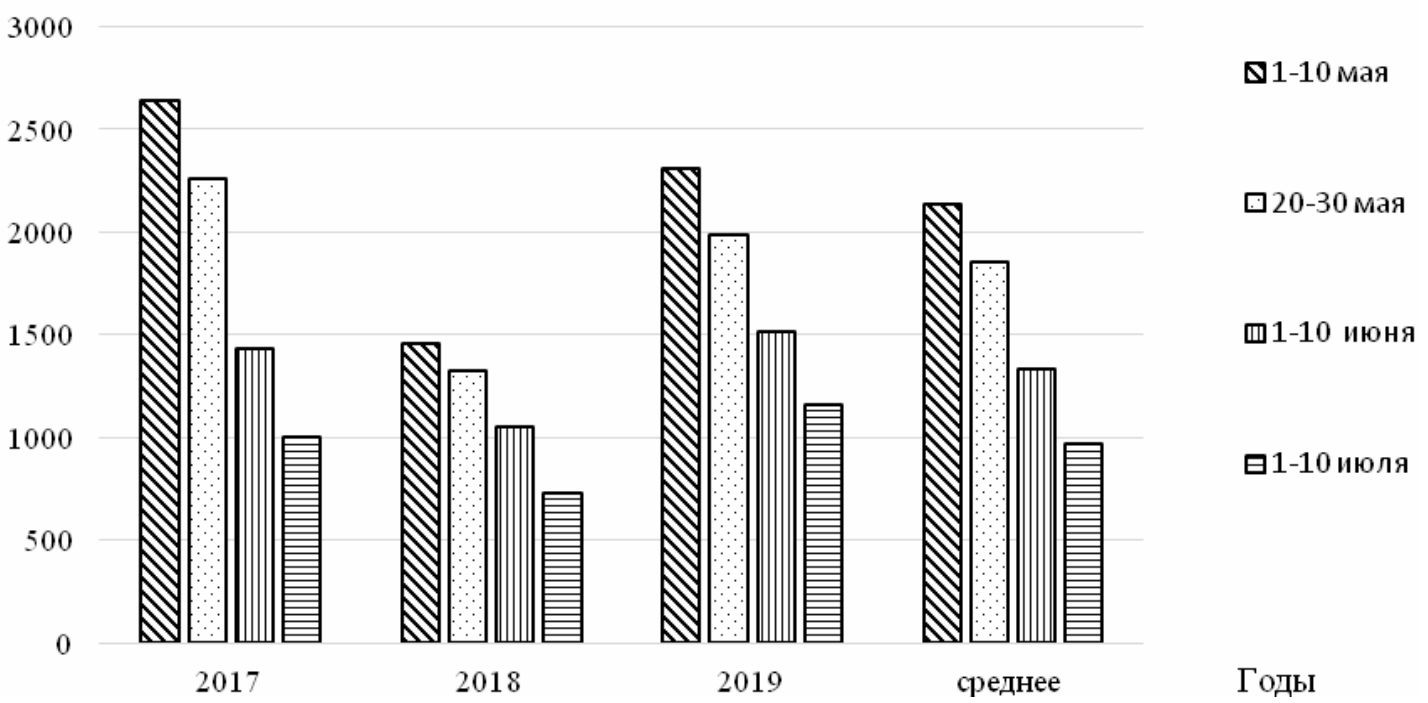

Puc. 2. Фотосинтетический потенциал люцерны изменчивой при различных сроках посева, тыс. м² сутки/га 
ное значение - 727 тыс. м² сутки/га отмечено на последнем посеве, проведенном в первой декаде июля, и был меньше в 1,41,6 раза, чем в другие годы исследований. Аналогичная закономерность прослеживается и по более ранним срокам посева.

Фотосинтетическую деятельность посевов характеризует не только площадь ассимиляционного аппарата и продолжительность его работы, но и продуктивность единицы листовой поверхности, которая выражается величиной чистой продуктивности фотосинтеза (ЧПФ) [12], то есть показателем общей сухой биомассы, образуемой растениями в течение суток, в расчете на квадратный метр листьев «работающих» в течение этого дня [11].

В первый год жизни ЧПФ находилась в диапазоне от 0,87 до 0,93 г/ м² сутки. В среднем за три года исследований наибольший показатель сформирован при ранних посевах (1-10 мая), что способствовало накоплению 2,0 т/га сухого вещества. Это связано, в первую очередь, с лучшей всхожестью семян и сохранностью растений. Из трех лет исследований наибольшие значения ЧПФ посевов наблюдались в 2017 году, причем на последнем сроке посева она была максимальной - 1,12 г/ м² сутки, так как июльские осадки на уровне нормы способствовали появлению дружных всходов и хорошему развитию растений. Но короткий период вегетации не позволил растениям достичь фризиологической зрелости и выход сухого вещества составил только 1,12 т/га против 2,55 т/га на ранневесенних посевах, где ЧПФ была ниже на $0,15 \mathrm{r} / \mathrm{m}^{2}$ сутки.

В последующие годы исследований ЧПФ снижается от первого срока посева к четвертому за счет снижения листовой поверхности, но более высокими были показатели в 2019 году. На ранневесеннем посеве она была на уровне посева в первой декаде мая 2017 года - 0,97 г/ м² сутки.

\section{Заключение}

Таким образом, сроки посева оказали влияние на рост и фотосинтетическую деятельность растений. Более интенсивное увеличение листовой поверхности на ранневесенних посевах способствовало активизации фотосинтеза и в конечном итоге влияло на продуктивность растений. Выход сухого вещества в год посева составил $0,9 \ldots 2,0$ т/га. Но как отмечают многие авторы [3, 15], индексы продуктивности фротосинтеза не стабильны и сильно зависят от условий среды обитания и степени воздействия человека на растительный организм.

\section{Лumepamypa}

1. Белкина, Р. И. Фотосинтетический потенциал и продуктивность сортов яровой пшеницы разных групп спелости в северной лесостепи Тюменской области / Р. И. Белкина, К. В. Моисеева, М. В. Поляков // Успехи современной науки. - 2017. - Т. 2. - № 4. - С. 153-156.

2. Биологическая азотфиксация клевера паннонского (Trifolium pannonicum Jacq.) в условиях Среднего Поволжья / А. Н. Кшникаткина, П. Г. Аленин, А. А. Галиуллин, С. А. Кшникаткин // Известия Самарского научного центра РАН. - 2018. - Т. 20. - № 5-2 (85). - С. 226-233.

3. Гущина, В. А. Фотосинтетическая деятельность агроценоза эхинацеи пурпурной / В. А. Гущина, Е. О. Никольская // Вестник Ульяновской государственной сельскохозяйственной академии. - 2013. - № 1 (21). - С. 10-13.

4. Дозоров, А. В. Фотосинтетическая деятельность сортов сои в зависимости от способов посева / А. В. Дозоров, Ю.В.Ермошкин // Вестник Ульяновской государственной сельскохозяйственной академии. - 2012. - № 1 (17). - С.8-12.

5. Доспехов, Б. А. Методика полевого опыта / Б. А. Доспехов. - Москва: Агропромиздат, 1985. $351 \mathrm{c}$.

6. Еряшев, А. П. О фотосинтетической деятельности посева козлятника восточного при использовании средств защиты растений / А. П. Еряшев, А. Г. Катаев, П. А. Еряшев // Кормопроизводство. - 2014. - № 6. - С. 17-20.

7. Изучение морфофизиологических показателей и чистой продуктивности фотосинтеза ярового ячменя, возделанного с применением биопрепаратов / Н. Е. Павловская, А. Г. Тимаков, И. В. Яковлева, В. В. Мамеев // Научный журнал Российского НИИ проблем мелиорации. - 2019. № 1 (33). - C. 153-167.

8. Методические указания по проведению полевых опытов с кормовыми культурами // под ред. Ю. К. Новоселова [и др.]. - Москва: ВНИИ кормов им. В. Р. Вильямса, 1983. - 198 с.

9. Ничипорович, А. А. Фотосинтез и теория получения высоких урожаев / А. А. Ничипорович. Москва: Издательство АН СССР, 1961. - 193 с.

10. Ничипорович, А. А. Фотосинтетическая деятельность растений как основа их продуктивности в биосфере и земледелии // Фотосинтез и продукционный процесс. - Москва: Наука, 1988. C. 5-29.

11. Соловьев, С. В. Агроприемы, регуляторы роста растений и чистая продуктивность фотосинтеза / С. В. Соловьев, А. И. Гераськин // Вестник МичГАУ. - № 2. - Ч.1. - 2011. - С. 99-103. 
12. Стасик, О. О. Фотосинтез и проблемы повышения продуктивности растений / О. О. Стасик, Д. А. Киризий, Г. А. Прядкина // Физиология растений и генетика. - 2013. - Т. 45. - № 6. - С. 501 515.

13. Тимошкин, О. А. Фотосинтетическая деятельность бобовых трав при применении микроудобрений и биорегуляторов / О. А. Тимошкин, О. Ю. Тимошкина, А. А. Яковлев // Достижения науки и техники АПК. - 2013. - № 7. - С. 58-60.

14. Шаповал, О. А. Влияние регуляторов роста растений и доз NPK на фотосинтетическую деятельность растений подсолнечника / О. А. Шаповал, Р. М. Алиев-Лещенко // Плодородие. 2014. - № 1 (76). - C. 2-4.

15. Cramer, W. A. Photosynthetik Cytochromes / W. A. Cramer, I. Whitmarsh // Annual Review of Plant Physiology. - 1977. - V. 28. - P 133-172.

16. Galler, J. Luzerne - ideal auch in Trockenperioden Fortsehr / J. Galler // Landwitzt. - 2000. - V. 14. - P. 10-14.

17. Lamb, J. F. Population Density and Harvest Maturity Effects on Leaf and Stem Yield in Alfalfa / J. F. Lamb, C. C. Sheaffer, D. A. Samac // Agronomy Journal. - 2003. - V. 95. - P. 582-611.

18. Leaf and stem properties of alfalfa entries / Sheaffer. C. C., Martin N. P., Lamb J. Ann F. S., Cuomo Greg R., Jewett Jane Grimbso, Quering Steven R. // Agronomy Journal. - 2000. - V. 92(4). - P. 733-739.

19. Stoy, V. Assimilatbildung und verteilung als Komponenten der Ertragsbildung beim Getreide / V. Stoy // Angewandte Botanik, 1973. - V. 47. - P. 17-26.

UDC $581.132+633.31$

DOI 10.36461/NP.2020.54.1.004

\section{SEEDING TIMES AND PHOTOSYNTHETIC ACTIVITY OF AGROCENOSIS OF VARIEGATED ALFALFA OF THE FIRST YEAR OF LIFE}

\section{A. Gushchina, Doctor of Agricultural Sciences, Professor; O. A. Timoshkin*, Doctor of Agricultural Sciences, Assistant-professor; G. V. Ilyina, Doctor of Biological Sciences, Professor; G. N. Volodkina, post-graduate}

Federal State Budgetary Educational Institution of Higher Education Penza State Agrarian University, Russia, t. 8(8412) 62-83-67, e-mail: guschina.v.a@pgau.ru

${ }^{*}$ Federal State Budgetary Scientific Institution_Federal Scientific Center for Bast Crops, the workers settlement of Lunino, Penza oblast, Russia, t. +7 (84161) 3-18-14, e-mail: oatimoshkin@mail.ru

Due to the wide range of cultivation of alfalfa and increasing the efficiency of its use in modern agriculture, it is necessary to introduce varieties of a new generation with a wide amplitude of resistance to abiotic stress factors. The development of methods for cultivating variegated alfalfa of the Dariya variety involves the use of reserves of photosynthetic activity to increase its productivity. Therefore, the aim of the research was to determine the optimal sowing period for variagated alfalfa, at which high yields could be formed due to the better use of the photosynthetic function of plants. The experiment was conducted on the experimental field of Penza Agricultural Institute - a branch of the Federal Center for Bast Crops in 2017-2019. The soil was leached chernozem (black soil). Four sowing periods were studied: the first - early spring (May, 1-10), coinciding with the physical ripeness of the soil; the second - late spring (May, 20-30); the other two were carried out in the summer period: the third - June, 1-10; and the fourth - in 30 days after the previous one. The years of the research were characterized as dry. The most optimal conditions for the development of the assimilation surface of plants of the first year of life were formed in early spring crops, where the leaf area was the largest -30.5 thousand $\mathrm{m}^{2} / \mathrm{ha}$. As the growing season decreased, a 1.5 times decrease in the leaf surface index was observed. The most intensive formation of the assimilation surface took place in 2017 and its area was 35.8...19.7 thousand $\mathrm{m}^{2} /$ ha, reaching its maximum during early sowing. In the same year, the highest value of photosynthetic potential of $1001 \ldots 2638$ thousand $\mathrm{m}^{2}$. day/ha was noted. On average, over three years, the maximum potential of 2129.3 thousand $\mathrm{m}^{2}$.day/ha was formed in plants during sowing in early spring, and the net productivity of photosynthesis was in the range from 0.87 to $0.93 \mathrm{~g} / \mathrm{m}^{2}$ day. The highest index was established during early sowing, which contributed to the accumulation of 2.0 t/ha of dry matter.

Key words: variegated alfalfa, sowing dates, net photosynthesis productivity, photosynthetic potential, productivity.

\section{References:}

1. Belkina, R. I. Photosynthetic potential and productivity of spring wheat varieties of different ripeness groups in the northern forest-steppe of the Tyumen region / R. I. Belkina, K. V. Moiseeva, M. V. Polyakov // Successes in modern science. - 2017. - v. 2. - № 4. - p. 153-156. 
2. Biological nitrogen fixation of Pannonian clover (Trifolium pannonicum Jacq.) in the Middle Volga region / A. N. Kshnikatkina, P. G. Alenin, A. A. Galiullin, S. A. Kshnikatkin // Bulletin of Samara Scientific Center of the Russian Academy of Sciences. - 2018. - v. 20. - № 5-2 (85). - p. 226-233.

3. Gushchina, V. A. Photosynthetic activity of agrocenosis of Echinacea Purpurea / V. A. Gushchina, E. O. Nikolskaya // Bulletin of Ulyanovsk State Agricultural Academy. - 2013. - № 1 (21). - p. 10-13.

4. Dozorov, A. V. Photosynthetic activity of soybean varieties depending on sowing methods / A. V. Dozorov, Yu. V. Ermoshkin // Bulletin of Ulyanovsk State Agricultural Academy. - 2012. - № 1 (17). p.8-12.

5. Dospekhov, B. A. Methods of field experiment / B. A. Dospekhov. - Moscow: Agropromizdat, 1985.- $351 \mathrm{p}$.

6. Eryashev, A. P. On the photosynthetic activity of sowing Eastern galega when using plant protection products / A. P. Eryashev, A. G. Kataev, P. A. Eryashev // Fodder production. - 2014. - № 6. - p. 17-20.

7. The study of morphophysiological indicators and the net productivity of photosynthesis of spring barley cultivated with the use of biological products / N. E. Pavlovskaya, A. G. Timakov, I. V. Yakovleva, V. V. Mameev // Scientific journal of the Russian Scientific Research Institute of Land Improvement Problems. - 2019.- № 1 (33). - p. 153-167.

8. Guidelines for conducting field experiments with fodder crops // Ed. by Yu. K. Novoselov [et al.]. Moscow: the All-Russian Williams Fodder Research Institute, 1983.- 198 p.

. Nichiporovich, A. A. Photosynthesis and the theory of obtaining high yields / A. A. Nichiporovich. Moscow: Publishing House of the Academy of Sciences of the USSR, 1961. - $193 \mathrm{p}$.

10. Nichiporovich, A. A. Photosynthetic activity of plants as the basis of their productivity in the biosphere and agriculture // Photosynthesis and production process. - Moscow: Nauka, 1988.- p. 5-29.

11. Solovyov, S. V. Agricultural practices, plant growth regulators and the net productivity of photosynthesis / S. V. Solovyov, A. I. Geraskin // Vestnik of MichSAU. - № 2. - Part 1. - 2011.- p. 99-103.

12. Stasik, O. O. Photosynthesis and problems of increasing plant productivity / O. O. Stasik, D. A. Kiriziy, G. A. Pryadkina // Plant Physiology and Genetics. - 2013. - v. 45. - № 6. - p. 501-515.

13. Timoshkin, O. A. Photosynthetic activity of legumes when using microelement fertilizers and bioregulators / O. A. Timoshkin, O. Yu. Timoshkina, A. A. Yakovlev // Dostizheniya nauki i tekhniki APK. 2013. - № 7. - p. 58-60.

14. Shapoval, O. A. The influence of plant growth regulators and doses of NPK on the photosynthetic activity of sunflower plants / O. A. Shapoval, R. M. Aliev-Leshchenko // Plodorodie. - 2014. - № 1 (76). - p. 2-4.

15. Cramer, W. A. Photosynthetik Cytochromes / W. A. Cramer, I. Whitmarsh_/ Annual Review of Plant Physiology. - 1977. - v. 28. - p. 133-172.

16. Galler, J. Luzerne - ideal auch in Trockenperioden Fortsehr / J. Galler // Landwitzt. - 2000. - v. 14. - p. 10-14.

17. Lamb, J. F. Population Density and Harvest Maturity Effects on Leaf and Stem Yield in Alfalfa / J. F. Lamb, C. C. Sheaffer, D. A. Samac // Agronomy Journal. - 2003. - v. 95. - p. 582-611.

18. Leaf and stem properties of alfalfa entries / Sheaffer. C. C., Martin N. P., Lamb J. Ann F. S., Cuomo Greg R., Jewett Jane Grimbso, Quering Steven R. // Agronomy Journal. - 2000. - v. 92(4). - p. 733-739.

19. Stoy, V. Assimilatbildung und verteilung als Komponenten der Ertragsbildung beim Getreide / V. Stoy // Angewandte Botanik, 1973. - v. 47. - p. 17-26. 